OPEN ACCESS

Edited by:

Qiaobao Zhang,

Xiamen University, China

Reviewed by:

Yan-Bing He,

Tsinghua University, China

Xianwen Wu,

Jishou University, China Hongshuai Hou,

Central South University, China

*Correspondence:

Chenghao Yang

esyangc@scut.edu.cn

Specialty section

This article was submitted to

Physical Chemistry and Chemical

Physics,

a section of the journal

Frontiers in Chemistry

Received: 28 June 2018

Accepted: 30 July 2018

Published: 04 September 2018

Citation:

Xu K, Li Y, Xiong J, OU X, SU W, Zhong $G$ and Yang C (2018) Activated Amorphous Carbon With

High-Porosity Derived From Camellia Pollen Grains as Anode Materials for

Lithium/Sodium Ion Batteries.

Front. Chem. 6:366.

doi: 10.3389/fchem.2018.00366

\section{Activated Amorphous Carbon With High-Porosity Derived From Camellia Pollen Grains as Anode Materials for Lithium/Sodium Ion Batteries}

\author{
Kaiqi Xu ${ }^{1}$, Yunsha $\mathrm{Li}^{1,2}$, Jiawen Xiong ${ }^{2}$, Xing Ou ${ }^{2}$, Wei Su ${ }^{1}$, Guobin $\mathrm{Zhong}^{1}$ and \\ Chenghao Yang ${ }^{2 \star}$ \\ ${ }^{1}$ Electric Power Research Institute of Guangdong Power Grid Co., Ltd., Guangzhou, China, ${ }^{2}$ Guangzhou Key Laboratory for \\ Surface Chemistry of Energy Materials, New Energy Research Institute, School of Environment and Energy, South China \\ University of Technology, Guangzhou, China
}

Carbonaceous anode materials are commonly utilized in the energy storage systems, while their unsatisfied electrochemical performances hardly meet the increasing requirements for advanced anode materials. Here, activated amorphous carbon (AAC) is synthesized by carbonizing renewable camellia pollen grains with naturally hierarchical structure, which not only maintains abundant micro- and mesopores with surprising specific surface area $\left(660 \mathrm{~m}^{2} \mathrm{~g}^{-1}\right)$, but also enlarges the interlayer spacing from 0.352 to $0.4 \mathrm{~nm}$, effectively facilitating ions transport, intercalation, and adsorption. Benefiting from such unique characteristic, AAC exhibits $691.7 \mathrm{mAh} \mathrm{g}^{-1}$ after 1200 cycles at $2 \mathrm{~A}$ $\mathrm{g}^{-1}$, and achieves 459.7, 335.4, 288.7, 251.7, and 213.5 $\mathrm{mAh}^{-1}$ at 0.1, 0.5, 1, 2, $5 \mathrm{~A}$ $\mathrm{g}^{-1}$ in rate response for lithium-ion batteries (LIBS). Additionally, reversible capacities of $324.8,321.6,312.1,298.9,282.3,272.4 \mathrm{mAh}^{-1}$ at various rates of $0.1,0.2,0.5,1$, $2,5 \mathrm{~A} \mathrm{~g}^{-1}$ are preserved for sodium-ion batteries (SIBs). The results reveal that the AAC anode derived from camellia pollen grains can display excellent cyclic life and superior rate performances, endowing the infinite potential to extend its applications in LIBs and SIBs.

Keywords: activated amorphous carbon, anode, high porosity, lithium ion batteries, sodium ion batteries

\section{INTRODUCTION}

The emergence and rapid development of portable electronic devices, electric vehicles and renewable energy industries urge preeminent large-scale energy storage and conversion systems, which exhibit superior energy density and specific capacity as well as phenomenal life-span with trustworthy safety (Hannan et al., 2017; Zhang et al., 2017). Among prevalent energy storage systems, lithium ion batteries (LIBs) and sodium ion batteries (SIBs) attract most attentions owing to their high working potential and extraordinary storage capacity (Shen et al., 2018). It is well-known that in order to promote practical applications of LIBs and SIBs, developing high-performing electrode materials are inevitable (Zheng et al., 2015; Luo et al., 2016). With increasing improvements in cathode materials, commercial graphite as the mainstream anode material gradually becomes dissatisfactory due to its limited theoretical capacity (372 $\mathrm{mAh} \mathrm{g}^{-1}$ for LIBs) (Hou et al., 2015; Zhang et al., 2016b). Besides, the highly regular distance between graphene layer $(0.335 \mathrm{~nm})$ can hardly accommodate the size of $\mathrm{Na}^{+}$, prohibiting the possibility 
to form stable Na-intercalation compounds (Irisarri et al., 2015; Yang et al., 2017). Though graphite hinders the improvement of LIBs and SIBs, carbonaceous materials still consumingly appeal to researchers, thanks to their significant advantages of low lithium/sodium ion insertion/desertion potential, highly structural stability, cost-efficiency, and sufficient resources (Hou et al., 2017a,b).

Amorphous carbon, compared to graphite, can reach higher specific capacity with enlarged interlayer distance and shortened ion transportation paths. Owing to environment amiability, sustainability and cost efficiency, ta large amount of diverse selectable biomass materials, such as protein (Li et al., 2013), peanut shell (Lv et al., 2015), bee pollen grain (Tang et al., 2016), rice husk (Zhang et al., 2016a), cotton (Li et al., 2016; Xiong et al., 2018; Yang et al., 2018), garlic skin (Zhang et al., 2018c), have been investigated in depth of their electrochemical capabilities. Generally, biomass-derived amorphous carbon can be synthesized by directly pyrolysis (Li et al., 2016) - (Wang et al., 2015) or hydrothermal treatment (Li et al., 2015). It is noted that most of the biomass-derived carbon can successful maintain the uniform sphere shape, inherent textile and hollow tubes. Despite of advantages of biomass-derived carbon, it is convinced that its electrochemical potential has not been ultimately exploited. To address this challenge, researchers have exerted their efforts on constructing inner microstructures and modifying surface properties of biomass-derived carbon by utilizing the activation methods (Gu et al., 2014; Wu et al., 2016a). Noticeably, chemical activation by mixing carbon materials and chemical reagents, $\mathrm{KOH}$ for instance, is less energy-consuming than physical activation resulting from the relatively low anneal temperature (Gao et al., 2016).

Pollen grains, distinctively, presenting uniformly discrete particle distribution and divergent particle shapes from various kinds of flowers, are usually employed in synthesis of various materials as templates (Chen et al., 2016). When regarded as anode for LIBs, cattail pollen carbon after physically activating exhibits $382 \mathrm{mAh} \mathrm{g}^{-1}$ at $25^{\circ} \mathrm{C}$ at rate of $37.2 \mathrm{~mA}$ $\mathrm{g}^{-1}$, distinguishing itself as a competitive candidate in anode materials beyond graphite (Tang et al., 2016). Impractical test current density is reason of the slightly better capacity, which still need further improvements. Therefore, further exploration of beneficiated activations for fabricating pollen grain's microstructure is required.

In this work, taking the advantage of pollen grains, we put forward a homogeneous and tunable synthetic method for activated amorphous carbon (AAC) derived from camellia pollen grains. Pollen grains were activated through chemical activation using $\mathrm{KOH}$ as activating reagent (Su et al., 2017), followed by a two-stage carbonization process. The eventual product is identified as poly-porous amorphous carbon with enhanced specific surface area around $660 \mathrm{~m}^{2} \mathrm{~g}^{-1}$ and enlarged layer distance from 0.35 to $0.4 \mathrm{~nm}$, which contributes to advanced specific capacities and cyclic performances with excellent rate when acting as anode materials for LIBs and SIBs. The outstanding characteristics provide camellia-pollen-grainderived carbon with the opportunity to meet the increasing demand of advanced storage devices.

\section{EXPERIMENTAL}

\section{Material Preparation}

The activated amorphous carbon was synthesized by annealing camellia pollen grain. After rinsing with acetone and deionized water, $3 \mathrm{~g}$ raw pollen grains were mixed with $80 \mathrm{~mL} \mathrm{KOH}$ solution $\left(0.025 \mathrm{~g} \mathrm{~mL}^{-1}\right)$ and stirred for $6 \mathrm{~h}$ at $40^{\circ} \mathrm{C}$, following by drying process at $80^{\circ} \mathrm{C}$. The obtained pollen grains were then transferred into a tube furnace and underwent the two-stage heat treatment under $\mathrm{N}_{2}$ atmosphere, which suggested maintaining temperature at $400^{\circ} \mathrm{C}$ for $1 \mathrm{~h}$ at the first stage and $800^{\circ} \mathrm{C}$ for $3 \mathrm{~h}$ at the second stage with the fixed heating rate of $5^{\circ} \mathrm{C} / \mathrm{min}$ for the entire calcination. Finally, the sample was etched by $3 \mathrm{M} \mathrm{HCL}$ and thoroughly washed with deionized water and desiccated at $80^{\circ} \mathrm{C}$ for $24 \mathrm{~h}$. The as-prepared activated amorphous carbon was denoted as AAC.

For comparison, another $3 \mathrm{~g}$ raw pollen grains were directly annealed through two-stage heat treatment aforementioned to acquire pristine amorphous carbon, denoting as AC.

\section{Material Characterizations}

Scanning electron microscope (SEM, FEIQuanta 200 FEG) and transmission electron microscope (TEM, Tecnai G2 F20 S-TWIN, Japan) were performed to unveil the morphology and microscopic structure of both samples. To gain the intrinsic features of the samples, X-ray diffraction (XRD, Bruker D8 Advance, Germany) ( $\mathrm{Cu}, \mathrm{K} \alpha, \lambda=1.5405 \AA$ ), Raman spectrometer (JOBIN-Yvon HR800) and X-ray photoelectron spectroscopy (XPS, Thermo/ESCALAB 250XI) were conducted. $\mathrm{N}_{2}$ adsorption/desorption isotherms for calculation of specific surface area (SSA) and accumulative pore volume based on Brunauer-Emmett-Teller and density functional theory methods was carried out on ASAP 2020 Micromeritics.

\section{Electrochemical Measurements}

The working electrode was fabricated using copper foil covered with slurry comprised of $70 \mathrm{wt} \%$ of AAC or AC, 20 wt \% of PVDF binder and $10 \mathrm{wt} \%$ carbon black. Subsequently the electrode is dried out with $0.5 \mathrm{mg} \mathrm{cm}^{-2}$ average active material loading to assemble CR2032 coin cells together with PE/PP films or glass-fiber papers as separators, metal lithium or sodium foils as counter electrodes and corresponding electrolyte $\left(1 \mathrm{M} \mathrm{LiPF}_{6}\right.$ or $1 \mathrm{M} \mathrm{NaCF}_{3} \mathrm{SO}_{3}$ in ethylene carbonate, dimethyl carbonate and ethyl methyl carbonate=1:1:1(v: v: v) for lithium ion batteries and sodium ion batteries, respectfully). CV and EIS results were attributed to the employment of CHI660A electrochemical workstations while galvanostatic charge/discharge profiles were resulted from the measurements of LAND CT2001A batterytesting instruments.

\section{RESULTS AND DISCUSSIONS}

The overall synthesis of AAC is shown in Figure 1. The $\mathrm{KOH}$ activation followed by carbonization and acid etching process are involved in this strategy to introduce poly-pores into the interior structures of camellia pollen grains (details in experimentally section). The microscopic morphologies of the 


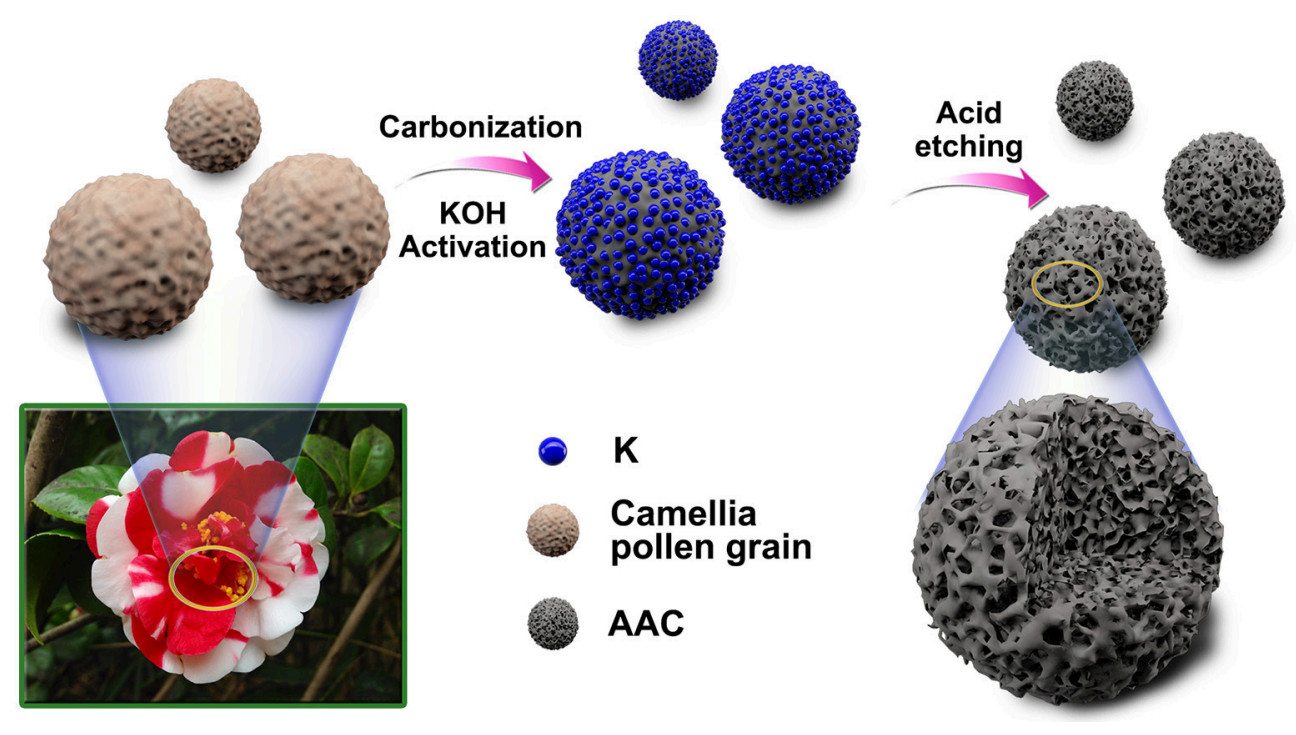

FIGURE 1 | Schematic illustration of the synthesis process for the activated amorphous carbon derived from camellia pollen grains.

original pollen grains, AC and AAC are analyzed via SEM, TEM and HRTEM images (Figure 2 and Figure S1). Camellia pollen grains are consisted of irregular spheres with rough surfaces, and the uniform diameter is about $30 \mu \mathrm{m}$ (Figures S1A,B). In comparison with AC (Figures S1C,D), Figures 2A,B visualizes that, in morphology, AAC possesses smooth surface, vast amount of mesopores and micropores, while primitive bulk shape is well-maintained, proving the effective function of $\mathrm{KOH}$ agent as impetus aiming at high porosity. Consistency can be found in corresponding TEM images (Figure 2C), in which explicit micro- and mesopores morphology. Moreover, it is noticeable in HRTEM (the inset figure of Figure 2D) that AAC is comprised of turbostratic nanodomains with $\sim 0.4 \mathrm{~nm}$ interlayer distance in average graphene interlayers. The evidence of dispersed diffraction ring in selected area electron diffraction pattern (SAED) can be observed, consistent with the HRTEM results, confirming the amorphous characteristic of AAC.

To gain a deeper insight of the composition and crystal structure of both samples, XRD patterns, and Raman spectra are investigated as displayed in Figures 3A-C. The broad peaks in XRD pattern referring to (002) facet are detected at $2 \theta$ of $21.8^{\circ}$ and $25^{\circ}$ for AAC and AC, respectively (Figure $2 \mathrm{~A}$ ), confirming the amorphous property of both samples. It is noted that the left shift of $2 \theta$ for AAC is ascribed to the enlarged interlayer. According to Bragg equation (Ou et al., 2016), interlayer distance between graphene layer can be calculated to be 0.409 and $0.352 \mathrm{~nm}$ for AAC and AC, respectively, both larger than $0.335 \mathrm{~nm}$ for graphite (Hou et al., 2017a). Such appealing expansion for AAC should be ascribed to $\mathrm{KOH}$ activation mechanism, which is explained by three steps as followed: (i) Firstly potassium-containing compounds commence etching carbon substrate to form the initial porous framework, which is called chemical activation. (ii) Then $\mathrm{H}_{2} \mathrm{O}$ and $\mathrm{CO}_{2}$ escape to impel the increment of porosity for physical activation. (iii) Metallic $\mathrm{K}$ permeates into carbon matrices, achieving the larger graphene interlayer distance, resulting in the lattices expansion (Romanos et al., 2012; Wang and Kaskel, 2012). The enlarged interlayer distance has favorable influences on the electrochemical performance of AAC, which enables reversible intercalation for $\mathrm{Li}^{+} / \mathrm{Na}^{+}$ion and well maintain the structural integrity at the same time (Wen et al., 2014; Kim et al., 2017; Zou et al., 2017; Yang et al., 2018; Zhu et al., 2018). Subsequently, Dband representing defects induction at $\sim 1334 \mathrm{~cm}^{-1}$ and G-band representing in-plane vibration at $\sim 1577 \mathrm{~cm}^{-1}$ are located in Raman spectra (Figure 3B), whereby the $\mathrm{I}_{\mathrm{D}} / \mathrm{I}_{\mathrm{G}}$ can be calculated as 0.84 for AAC and 1.11 for AC. Furthermore, based on the $\mathrm{I}_{\mathrm{D}} / \mathrm{I}_{\mathrm{G}}$ ratio, the $\mathrm{AAC}$ is of higher graphitization degree, providing a crucial foundation for improving electrical conductivity (Lv et al., 2015; Zhang et al., 2018c).

In addition, $\mathrm{N}_{2}$ adsorption/desorption isotherms measurement and differential pore volume distributions are tested for both sample in Figure 3C. The specific surface area (SSA) of AAC dramatically increases from 21.32 to 660.05 $\mathrm{m}^{2} \mathrm{~g}^{-1}$. While concurrently the accumulative pore volume of AAC scales up to $0.29 \mathrm{~cm}^{3} \mathrm{~g}^{-1}$, overwhelming larger than the AC of merely $0.01253 \mathrm{~cm}^{3} \mathrm{~g}^{-1}$. Unlike AC showing negligible few pores, AAC contains ample micropores and mesopores concentrating at $\sim 6$ and $11 \mathrm{~nm}$. The improved SSA and porosity, resulted from synergic effect between the chemical conversion of $\mathrm{KOH}$ and formation of $\mathrm{H}_{2} \mathrm{O}$ and $\mathrm{CO}_{2}$, offers not only extra active sites for $\mathrm{Li}^{+} / \mathrm{Na}^{+}$ion but also shortened ion transportation path with reduced inner resistance (Yu et al., 2016). To understand the existing chemical states of all elements in AAC, XPS measurement is characterized. Judging from XPS curve as displayed in Figure 3D, the peaks at 285.08 and $534.08 \mathrm{eV}$ are attributed to $\mathrm{C}$ and $\mathrm{O}$ elements, yielding an occupancy of 94.56 and rest $5.44 \%$, respectively. Individually, as displayed in Figures 3E,F, four predominant peaks are specified 

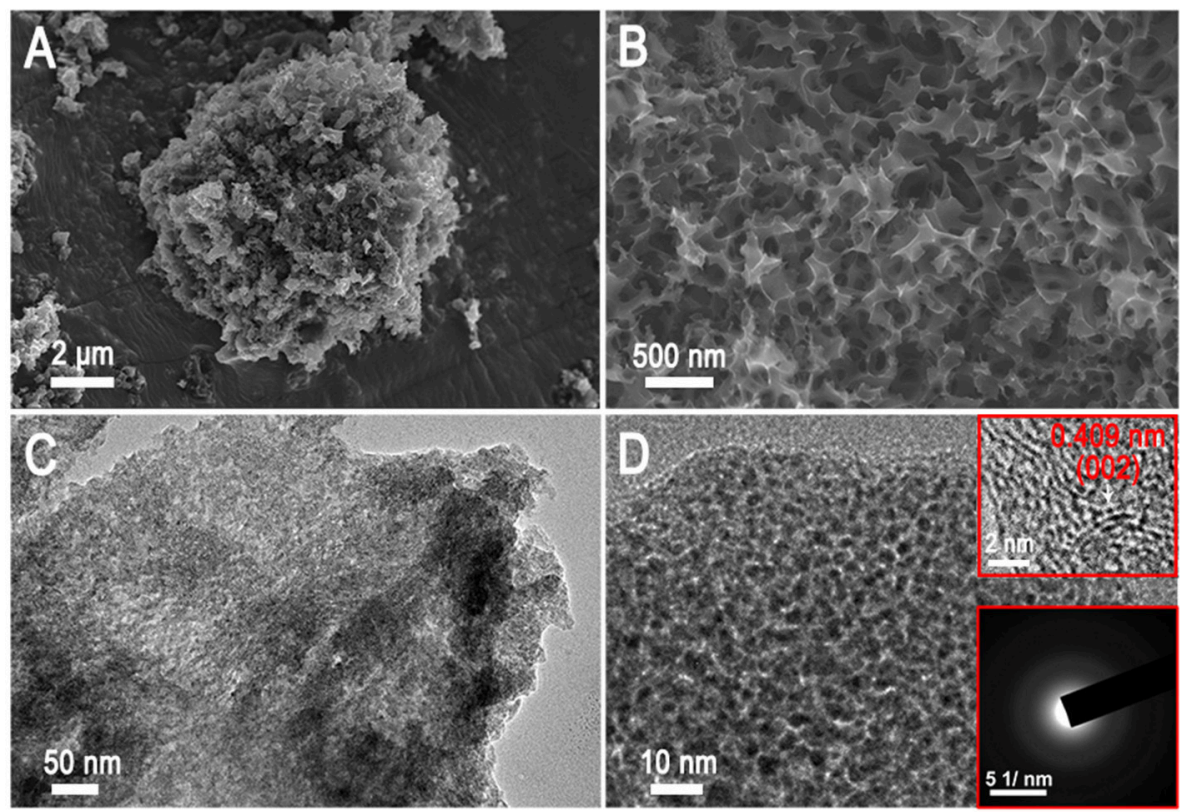

FIGURE 2 | (A, B) SEM images and (C, D) TEM images of AAC (the inner figures are SAED and HRTEM).
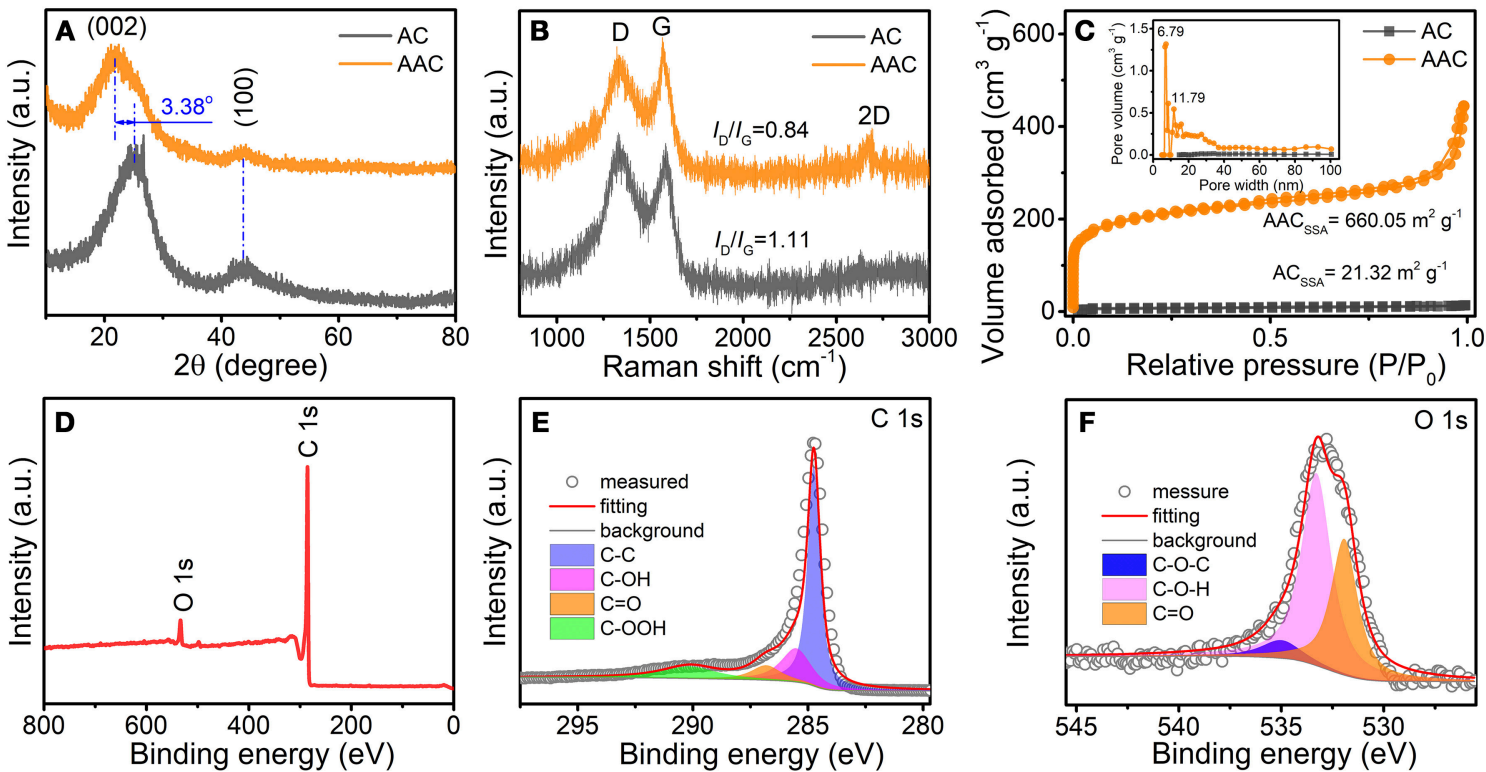

FIGURE 3 | (A) XRD patterns, (B) Raman spectra, and (C) $N_{2}$ sorption isotherms (inner figure is pore size distributions) of AAC and AC; (D) XPS survey scan spectrum of AAC; (E,F) high resolution XPS spectra of (E) $C 1 \mathrm{~s}$ and $(\mathbf{F}) 01 \mathrm{~s}$.

as $\mathrm{C}-\mathrm{C}(284.78 \mathrm{eV}), \mathrm{C}-\mathrm{OH}(285.48 \mathrm{eV}), \mathrm{C}=\mathrm{O}(286.88 \mathrm{eV})$, and $\mathrm{C}-\mathrm{OOH}(290.08 \mathrm{eV})$ in deconvoluted C 1s spectrum. Besides, three apparent peaks in deconvoluted $\mathrm{O} 1 \mathrm{~s}$ spectrum are assigned to the representative $\mathrm{C}=\mathrm{O}(531.88 \mathrm{eV}), \mathrm{C}-\mathrm{O}-\mathrm{H}(533.28 \mathrm{eV})$, and C-O-C (534.98 eV) (Lin et al., 2016; Li et al., 2017a).

Figure 4 illustrates the electrochemical performances of AAC and $\mathrm{AC}$ as anode materials for LIBs. Electrochemical behaviors of
$\mathrm{AAC}$ and AC during the initial three cycles are examined through cyclic voltammetry $(\mathrm{CV})$ test at a scan rate of $0.1 \mathrm{mV} \mathrm{s}^{-1}$ within voltage range between 0.01 and $3.0 \mathrm{~V}$, as presented at Figure $4 \mathrm{~A}$ and Figure S3A, respectively. Like AC sample, three identifiable cathodic peaks for AAC, which center at range of $1.8-0.4 \mathrm{~V}$ in the first CV curves and vanish in the following cycles are ascribed to the formation of irreversible solid electrolyte interface (SEI) and 

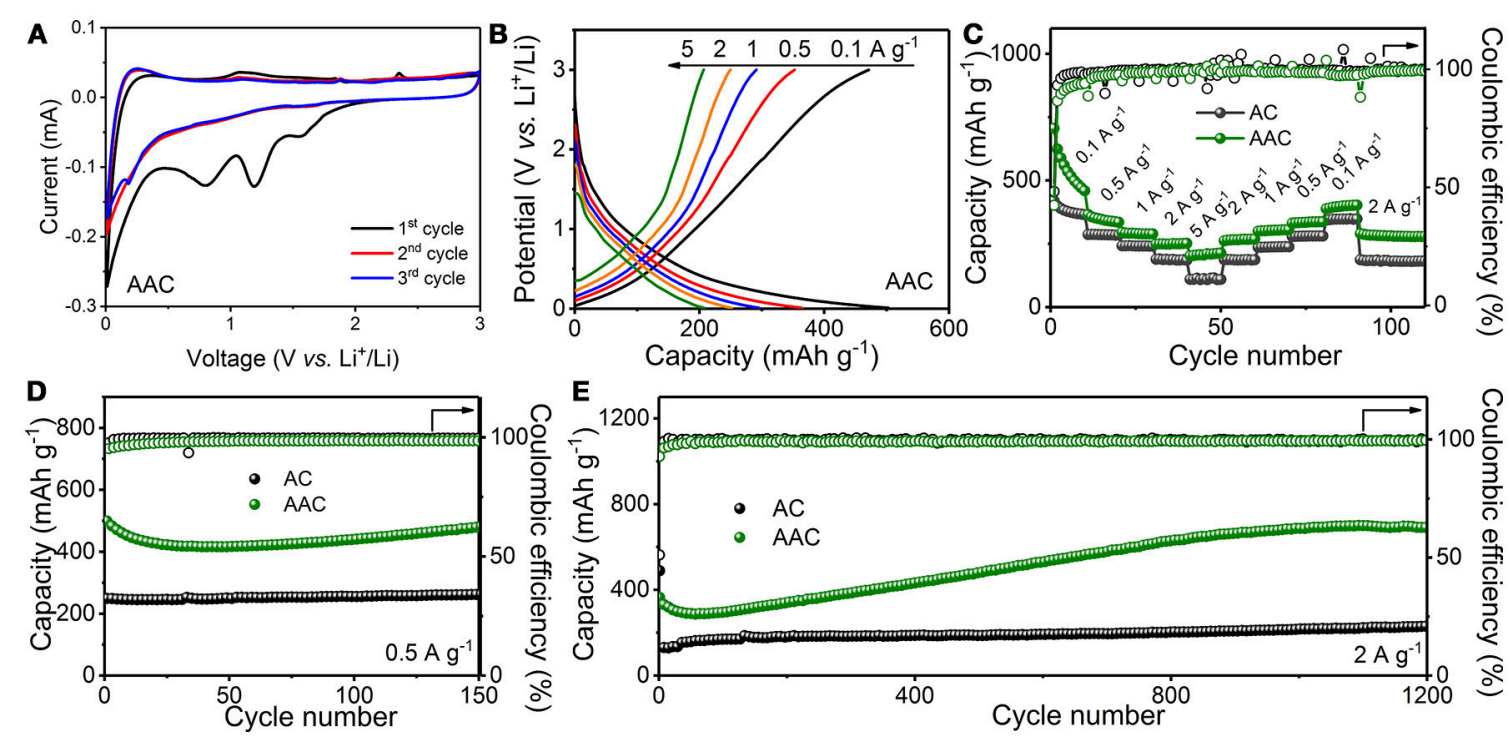

FIGURE 4 | Electrochemical performances of AAC and AC as anode materials for LIBs: (A) cyclic voltammetry (CV) curves at $0.1 \mathrm{mV} \mathrm{s}^{-1}$ of $\mathrm{AAC}$; (B) charge/discharge curves of AAC at different current densities; (C) rate performances; (D,E) long-term cyclic performances at $0.5 \mathrm{~A} \mathrm{~g}^{-1}$ (D) and $2 \mathrm{~A} \mathrm{~g}^{-1}$ (E).

unanticipated side reactions due to the consumption of oxygenic functional groups (Lv et al., 2015; Li et al., 2017b; Huang et al., 2018) Meanwhile, a reversible cathodic peak appears at potential window of $0.5-0.01 \mathrm{~V}$, in concert with the anodic peak at $0.2 \mathrm{~V}$, is originated from the reversible lithiation/delithiation process. It is observed that the 2nd and 3rd cycle of CV curves are scarcely discriminated, suggesting that SEI films formed at the first cycles securely protect the structural integrity of $\mathrm{AAC}$ an $\mathrm{AC}$, and enduring the rapid ion insert/extraction. Correspondently, the first galvanostatic charge/discharge portrait at $0.1 \mathrm{~A} \mathrm{~g}^{-1}$ for AAC (Figure S2A) shows charge and discharge plateaus at around 1.6 and $1.2 \mathrm{~V}$, respectively, which are generated from unavoidable SEI fabrication and electrolyte decomposition, leading to an irreversible capacity loss. Therefore, the charge and discharge capacities of AAC for the first cycle are $777.8 \mathrm{mAh} \mathrm{g}^{-1}$ and 1803.8 $\mathrm{mAh} \mathrm{g}^{-1}$, with initial coulombic efficiency (ICE) about $43.12 \%$, which is exceeding the AC anode.

Evaluation of rate performance for AAC anode is conducted by gradient current densities, as depicted in Figures 4B,C. AAC anode achieves the charge capacities of 459.7, 335.4, 288.7, 251.7, and $213.5 \mathrm{mAh}^{-1}$ at rate of $0.1,0.5,1,2$, and $5 \mathrm{~A} \mathrm{~g}^{-1}$, respectively, whereas AC delivers an overall inferior performance with unsatisfactory capacity decline at high current density of $5 \mathrm{~A}$ $\mathrm{g}^{-1}$ (Figure S3B). When the current density decreases from 5 to $0.1 \mathrm{~A} \mathrm{~g}^{-1}$ by stages, the charge capacity of AAC are restored to nearly $100 \%$ compared with the pristine state, reflecting the outstanding rate tolerance and stable structural maintenance of AAC. In galvanostatic charge/discharge test (Figures 4D,E), the charge capacity of AAC attractively reaches $479.2 \mathrm{mAh} \mathrm{g}^{-1}$ after 150 cycles at a current density of $0.5 \mathrm{~A} \mathrm{~g}^{-1}$ with $96 \%$ retention. Furthermore, it can achieve reversible capacity of $691.7 \mathrm{mAh} \mathrm{g}^{-1}$ after 1200 cycles at a high rate of $2 \mathrm{~A} \mathrm{~g}^{-1}$ with an ascending tendency in the first few hundred cycles, which is stemmed from gradual electrochemical activation of AAC and is similar to most carbonaceous anode materials (Qie et al., 2012; Lv et al., 2015; Xiong et al., 2018; Yang et al., 2018; Zhang et al., 2018b). On the contrary, ordinary AC merely delivers $261.6 \mathrm{mAh}^{-1}$ at $0.5 \mathrm{~A} \mathrm{~g}^{-1}$ and $229.1 \mathrm{mAh}$ $\mathrm{g}^{-1}$ at $2 \mathrm{~A} \mathrm{~g}^{-1}$ under the same cycling condition. Conspicuous improvements in electrochemical performance for AAC anode can be explained by synergistic effort of highly porous structure and expanded interlayer of $\mathrm{d}_{002}$ plane due to $\mathrm{KOH}$ activation. Specifically, the interface between electrode and electrolyte is modified by multiple pores for wide wettability, facilitating a much more efficient accesses for ions transportation through minimizing inherent impedance and shorten the diffusion paths. Besides, the larger interlayer distance favors the reversibility of ion intercalation and extraction. Furthermore, taking the advantages of this unique structure, additional active sites for Liions adsorption are provided, and integral structure to mitigate volume variation are guaranteed, making AAC into a favorable anode material for LIBs (Qin et al., 2014; Xiong et al., 2016, 2017).

For further evidences, CV curves acquired at different scan rate varied from 0.1 to $10.0 \mathrm{mV} \mathrm{s}^{-1}$ with similar feature are shown in Figure 5A. Capacitive behavior of AAC is estimated via the following equation:

$$
i(\mathrm{~V})=\mathrm{k}_{1} v+\mathrm{k}_{2} v^{1 / 2}
$$

or:

$$
i(\mathrm{~V}) / v^{1 / 2}=\mathrm{k}_{1} v^{1 / 2}+\mathrm{k}_{2}
$$

where $i$ is the responsive current at various scan rates $(v)$ at randomly chosen potential $(\mathrm{V})$, and $\mathrm{k}$ (both $\mathrm{k}_{1}$ and $\mathrm{k}_{2}$ ) are constants. $\mathrm{k}_{1}$ can be attained by calculating the slope of the liner relationship between $i(V) / v^{1 / 2}$ and $v^{1 / 2}$ at every fixed potential, 

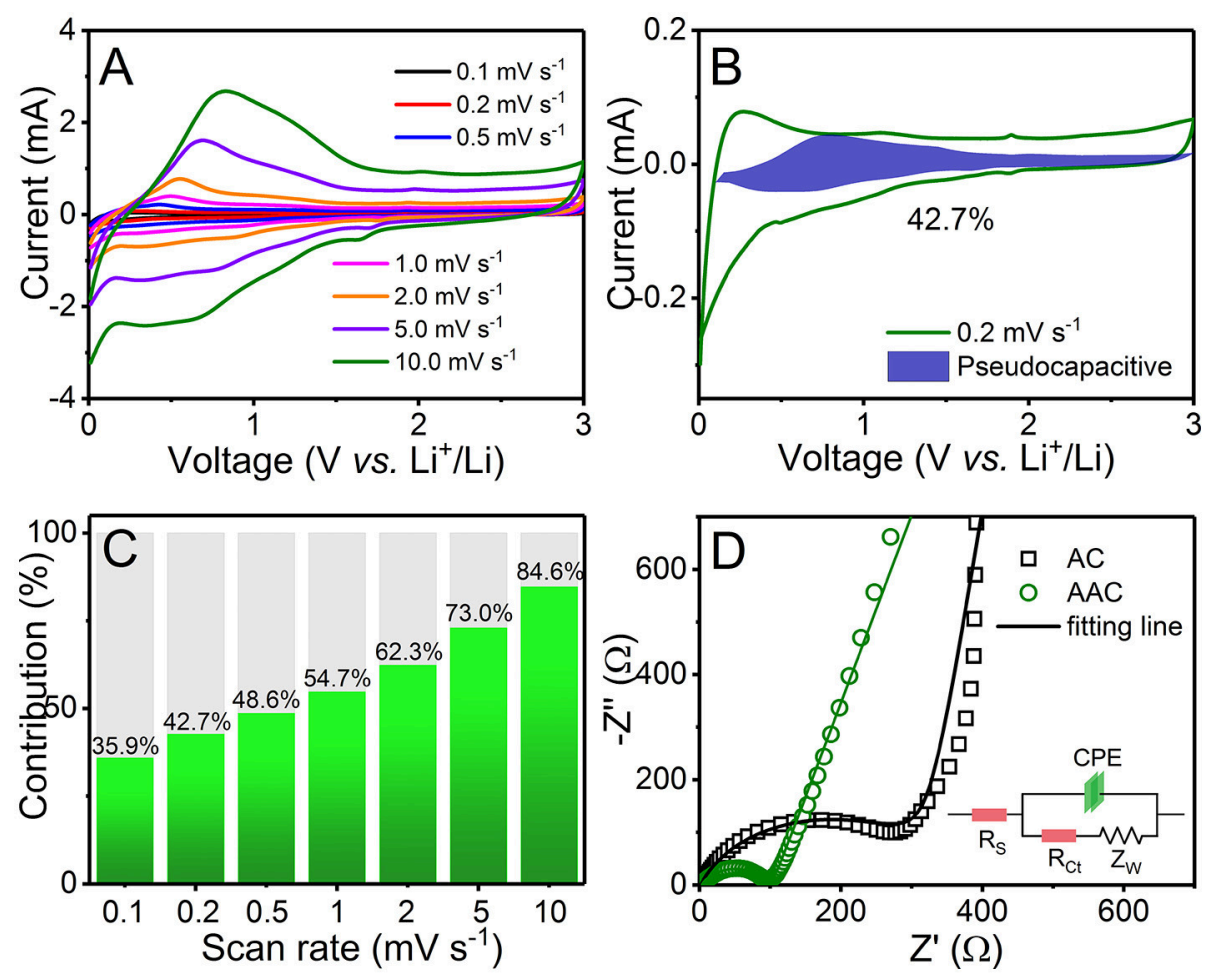

FIGURE 5 | (A) CV curves measured between 0.01 and 3.0 V at different sweep rate from 0.1 to $10.0 \mathrm{mV} \mathrm{s} \mathrm{s}^{-1}$; (B) CV curve with a blue closed area representing pseudocapacitance at a sweep rate of $0.2 \mathrm{mV} \mathrm{s}^{-1}$; (C) bar chart of pseudocapacitive contribution at corresponding sweep rate; (D) electrochemical impedance spectra in form of Nyquist plots of $\mathrm{AAC}$ and $\mathrm{AC}$ before cycling with equivalent circuit diagram as the inset.

evaluating the proportion of charge storage from capacitance and calculating capacity contributions from pseudocapacitance and diffusion (Chen et al., 2017; Wang et al., 2018; Zhang et al., 2018a). As scan rate increases, capacitive distribution increases in the same time and achieves $42.7 \%$ at a scan rate of $0.2 \mathrm{mV}$ $\mathrm{s}^{-1}$ (Figures 5B,C). When tested at a scan rate of $10 \mathrm{mV} \mathrm{s}{ }^{-1}$, the capacitive distribution can reach as high as $84.6 \%$. The $\mathrm{Li}^{+}$ions are easy to make absorption or reactions in macromicropores, resulting in the pseudocapacitive behavior at edges or on the surface of amorphous carbon. The higher ratio of pseudocapacitance allows charges to transfer in an effective way. With rational design and modification of AAC anode, excellent rate capability can be accomplished by reallocating the proportion of capacitive contribution to a more dominant occupancy. In order to confirm the smaller resistance of AAC, the electrochemical impedance spectroscopies (EIS) for AAC and $\mathrm{AC}$ anodes are carried out in Figure 5D. Obviously, the chargetransfer resistance $\left(\mathrm{R}_{\mathrm{ct}}\right)$ of AAC located in high frequency is much smaller than $A C$, reducing from 319.5 to $89.07 \Omega$, which results in the considerably improved electronic conductivity and reaction kinetics (Wu et al., 2016b, 2017). In accordance with capacity distribution, the effective rate response of AAC can be ascribed to the excellent reaction dynamics (Wang et al., 2018).

The increasing price for Li-containing cathodes incents researchers to seek for alternative energy storage system, among which SIB is suitable and promising. Therefore, with the instruction of the employment in LIBs, the AAC can be also applied for SIBs (Figure 6). Figure 6A and Figure S3C present the $\mathrm{CV}$ curves of $\mathrm{AAC}$ and $\mathrm{AC}$ performed at a sweep rate of $0.1 \mathrm{mV} \mathrm{s}^{-1}$ within $0.01-3.0 \mathrm{~V}$, respectively. Analyzing the $\mathrm{CV}$ curve of AAC anode (Figure 6A), it can observe a broad hump with two protuberant peaks at 1.0 and $0.4 \mathrm{~V}$, which are disappeared in next two cycles. These irreversible peaks should be assigned to the formation of protective SEI film and undesirable reactions of oxygen-containing functional groups (Zhu et al., 2018), and this analogous phenomenon is also demonstrated in CV profiles of AC anode (Figure S3D) While a redox peak at 0.03 and $0.06 \mathrm{~V}$ is observed, referring to $\mathrm{Na}^{+}$ion insertion/extraction. The overlapped $\mathrm{CV}$ profiles after the first cycle indicate a fully covered SEI film on AAC, suggesting the highly reversible redox reaction and stable structure. As shown in Figure S2B, AAC anode can exhibit an initial charge capacity of $328.7 \mathrm{mAh} \mathrm{g}^{-1}$ with the coulombic efficiency about $70 \%$, while it maintains almost $100 \%$ columbic efficiency in the succeeding charge/discharge cycles. It is worth noticing that the initial coulombic efficiency of AAC is surprisingly higher than AC (Figure S2B), which can be reasonably elucidated to the activation of AAC. Based on adsorption-insertion sodium storage mechanism of amorphous carbon (Hou et al., 2017a; Li et al., 2017c), increasing amount of active sites (pores and defects) can attract more $\mathrm{Na}^{+}$ion and the enlarged interlayer spacing is found suitable for $\mathrm{Na}^{+}$intercalation/extraction between interlayers. 

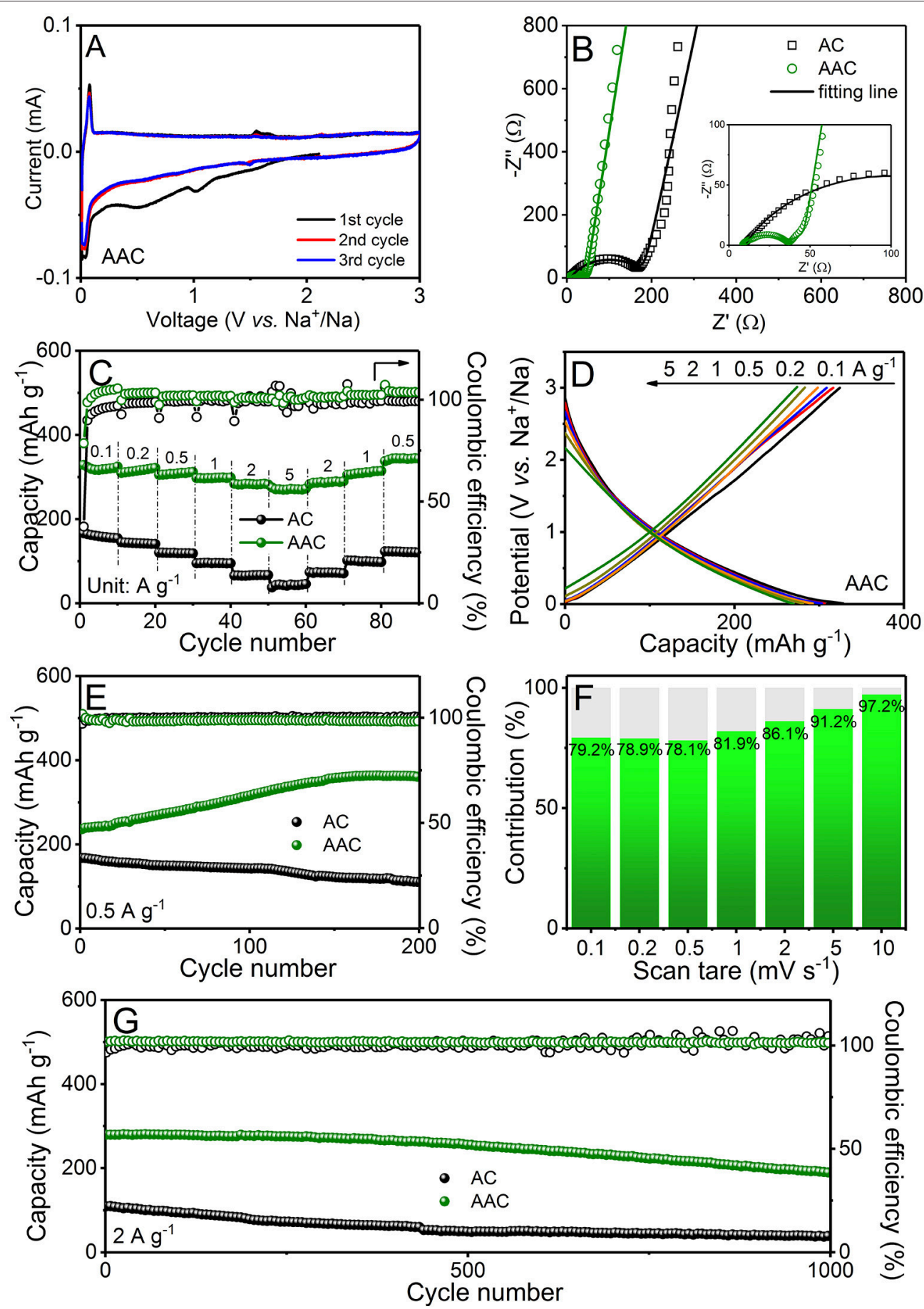

FIGURE 6 | Electrochemical measurements of AAC and AC as anode materials for SIBs: (A) cyclic voltammetry (CV) curves at 0.1 mV $\mathrm{s}^{-1}$ of $\mathrm{AAC}$; (B) electrochemical impedance spectra in form of Nyquist plots of AAC and AC before cycling with detailed view in high frequency area as the inset; (C) rate performances of $\mathrm{AAC}$ and $\mathrm{AC}$ and (D) charge/discharge curves of $\mathrm{AAC}$ at different current densities; (E) long-term cyclic performances at $0.5 \mathrm{~A} \mathrm{~g}^{-1}$; (F) bar chart of pseudocapacitive contribution at various sweep rate; (G) long-term cyclic performances at $2 \mathrm{~A} \mathrm{~g}^{-1}$.

The comparison of AAC and AC anodes is measured sequentially at different current rates from 0.1 to $5 \mathrm{~A} \mathrm{~g}^{-1}$ (Figures 6C,D). The reversible capacities of AAC anode at every rate are much higher than $\mathrm{AC}$ anode, reaching to $324.8,321.6$, $312.1,298.9,282.3$, and $272.4 \mathrm{mAh} \mathrm{g}^{-1}$ at $0.1,0.2,0.5,1.0$, 2.0 , and $5.0 \mathrm{~A} \mathrm{~g}^{-1}$, respectively. Surprisingly, it can recover to 
$343.5 \mathrm{mAh} \mathrm{g}^{-1}$ when current density rolls back to $0.5 \mathrm{~A} \mathrm{~g}^{-1}$, indicating the superior rate performance. Besides, the long-term galvanostatic charge/discharge property of AAC and AC anodes are presented in Figures 6E,G. AAC anode obtains a charge capacity of $361.7 \mathrm{mAh} \mathrm{g}^{-1}$ at $0.5 \mathrm{~A} \mathrm{~g}^{-1}$ after 200 cycles and maintains $189.1 \mathrm{mAh} \mathrm{g}^{-1}$ at high rate of $2 \mathrm{~A} \mathrm{~g}^{-1}$ beyond 1000 cycles, surpassing the AC anode, which possesses awfully low charge capacity of only $113.1 \mathrm{mAh} \mathrm{g}^{-1}$ and $41.1 \mathrm{mAh} \mathrm{g}^{-1}$ at $0.5 \mathrm{~A} \mathrm{~g}^{-1}$ and $2 \mathrm{~A} \mathrm{~g}^{-1}$, respectively, with continuous degradation. The above enhanced cycling performance is originated from the three-dimension hierarchical porous structure equipped with well-fabricated SEI film as well as intrinsic shortened transport routes and facile intercalation for $\mathrm{Na}^{+}$(Ou et al., 2017).

EIS measurements (Figure 6B) validate the excellent cyclic and rate capability of AAC by simulating the equivalent circuits. Figure 6B displays that AAC exhibits satisfactory low impedance $\mathrm{R}_{\mathrm{ct}}$ of about $26.2 \Omega$, which is much smaller than that of AC $(160.3 \Omega)$, proving the low charge transfer resistance and fluent reaction process in AAC. Furthermore, the calculation of pseudocapacitive contributions at various sweep rates are also carried out in Figure 6F and Figure S4. Capacitive behavior of AAC is accountable for $78.9 \%$ of total capacity at sweep rate of $0.2 \mathrm{mV} \mathrm{s}^{-1}$, signifying that the critical capacitive behavior induced by larger specific surface area ensures the outstanding cyclic and rate performance of AAC. Compared with other published carbon anodes (Tables S1 and S2), it confirms that AAC exhibits attracting electrochemical performance for both lithium and sodium storage.

\section{CONCLUSION}

In general, the activated amorphous carbon (AAC) with porous structure derived from renewable camellia pollen grains is synthesized by a facile approach of homogeneous $\mathrm{KOH}$ activation followed by carbonization. AAC exhibits the enhancement in specific surface area $\left(660.04 \mathrm{~m}^{2} \mathrm{~g}^{-1}\right)$, the enrichment in micro/mesopores $\left(0.29 \mathrm{~cm}^{3} \mathrm{~g}^{-1}\right.$ for accumulated pore volume) and the enlargement in interlayer distance (from 0.352 to $0.409 \mathrm{~nm}$ ) as well. Furthermore, the modified microstructure can facilitate the infiltration for electrolyte

\section{REFERENCES}

Chen, L.-F., Ma, S.-X., Lu, S., Feng, Y., Zhang, J., Xin, S., et al. (2016). Biotemplated synthesis of three-dimensional porous $\mathrm{MnO} / \mathrm{C}-\mathrm{N}$ nanocomposites from renewable rapeseed pollen: an anode material for lithium-ion batteries. Nano Res. 10, 1-11. doi: 10.1007/s12274-016-1283-7

Chen, Z., Wu, R., Liu, M., Wang, H., Xu, H., Guo, Y., et al. (2017). General synthesis of dual carbon-confined metal sulfides quantum dots toward highperformance anodes for sodium-ion batteries. Adv. Funct. Mater. 27:1702046. doi: 10.1002/adfm.201702046

Gao, Z., Zhang, Y., Song, N., and Li, X. (2016). Biomass-derived renewable carbon materials for electrochemical energy storage. Mater. Res. Lett. 5, 69-88. doi: 10.1080/21663831.2016.1250834

Gu, X., Wang, Y., Lai, C., Qiu, J., Li, S., Hou, Y., et al. (2014). Microporous bamboo biochar for lithium-sulfur batteries. Nano Res. 8, 129-139. doi: 10.1007/s12274-014-0601-1 into the interior of AAC electrode. On the other hand, it accesses the efficient transportation of $\mathrm{Li}^{+} / \mathrm{Na}^{+}$ions by lowering the charge transfer resistance and shorten the diffusion paths. It is noted that the intercalation and adsorption of $\mathrm{Li}^{+} / \mathrm{Na}^{+}$ion are coincidentally promoted, leading to the outstanding electrochemical performances. As a result, AAC anode surprisingly achieves a reversible charge capacity of 691.7 $\mathrm{mAh} \mathrm{g}^{-1}$ after 1200 cycles at $2.0 \mathrm{~A} \mathrm{~g}^{-1}$ and $213.5 \mathrm{mAh} \mathrm{g}^{-1}$ at ultrahigh rate of $5.0 \mathrm{~A} \mathrm{~g}^{-1}$ for LIBs. Moreover, AAC delivers reversible capacities of $324.8,321.6,312.1,298.9,282.3$, and $272.4 \mathrm{mAh} \mathrm{g}^{-1}$ at $0.1,0.2,0.5,1.0,2.0$, and $5.0 \mathrm{~A} \mathrm{~g}^{-1}$ in gradient rate tests for SIBs. It has been discussed in plenty of articles that, concentration of activating reagent $(\mathrm{KOH}$ in this article) and activation duration are mutually responsible for the eventualities, which means that with rational adjustments can we delicately tailor the microstructure of pollen-grainderived amorphous carbon. Alone with the particularity of pollen grains as a renewable and cost-effective biomass, the activated amorphous carbon with such intriguing structure is likely to become the future promising anode materials for lithium and sodium ion batteries.

\section{AUTHOR CONTRIBUTIONS}

$\mathrm{KX}$ and JX conducted the experiments, CY is the supervisor of this research work. YL and XO helped writing. KX, YL, and XO performed the characterization and data analysis. All authors involved the analysis of experimental data and manuscript preparation.

\section{ACKNOWLEDGMENTS}

We gratefully acknowledge the financial support from the Guangdong Power Grid Co., Ltd (Grant No. GDKJXM20161890).

\section{SUPPLEMENTARY MATERIAL}

The Supplementary Material for this article can be found online at: https://www.frontiersin.org/articles/10.3389/fchem. 2018.00366/full\#supplementary-material

Hannan, M. A., Lipu, M. S. H., Hussain, A., and Mohamed, A. (2017). A review of lithium-ion battery state of charge estimation and management system in electric vehicle applications: challenges and recommendations. Renew. Sust. Energ. Rev. 78, 834-854. doi: 10.1016/j.rser.2017.05.001

Hou, H., Banks, C. E., Jing, M., Zhang, Y., and Ji, X. (2015). Carbon quantum dots and their derivative $3 \mathrm{D}$ porous carbon frameworks for sodium-ion batteries with ultralong cycle life. Adv. Mater. 27, 7861-7866. doi: 10.1002/adma.201503816

Hou, H., Qiu, X., Wei, W., Zhang, Y., and Ji, X. (2017a). Carbon anode materials for advanced sodium-ion batteries. Adv. Energy. Mater. 7:1602898. doi: 10.1002/aenm.201602898

Hou, H., Shao, L., Zhang, Y., Zou, G., Chen, J., and Ji, X. (2017b). Large-Area carbon nanosheets doped with phosphorus: a high-performance anode material for sodium-ion batteries. Adv. Sci. 4:1600243. doi: 10.1002/advs.201600243

Huang, S., Li, Z., Wang, B., Zhang, J., Peng, Z., Qi, R., et al. (2018). NDoping and defective nanographitic domain coupled hard carbon nanoshells 
for high performance lithium/sodium storage. Adv. Funct. Mater. 28:1706294. doi: 10.1002/adfm.201706294

Irisarri, E., Ponrouch, A., and Palacin, M. R. (2015). Review-hard carbon negative electrode materials for sodium-ion batteries. J. Electrochem. Soc. 162, A2476A2482. doi: 10.1149/2.0091514jes

Kim, H. S., Cook, J. B., Lin, H., Ko, J. S., Tolbert, S. H., Ozolins, V., et al. (2017). Oxygen vacancies enhance pseudocapacitive charge storage properties of $\mathrm{MoO}_{3-\mathrm{x}}$. Nat. Mater. 16, 454-460. doi: 10.1038/nmat4810

Li, R., Huang, J., Xu, Z., Qi, H., Cao, L., Liu, Y., et al. (2017a). Controlling the thickness of disordered turbostratic nanodomains in hard carbon with enhanced sodium storage performance. Energy Tech. 6, 1080-1087. doi: 10.1002/ente.201700674

Li, Y., Hu, Y.-S., Titirici, M.-M., Chen, L., and Huang, X. (2016). Hard carbon microtubes made from renewable cotton as high-performance anode material for sodium-ion batteries. Adv. Energy Mater. 6:1600659. doi: 10.1002/aenm.201600659

Li, Y., Xu, S., Wu, X., Yu, J., Wang, Y., Hu, Y.-S., et al. (2015). Amorphous monodispersed hard carbon micro-spherules derived from biomass as a high performance negative electrode material for sodium-ion batteries. J. Mater. Chem. A 3, 71-77. doi: 10.1039/C4TA05451B

Li, Y.-Q., Li, J.-C., Lang, X.-Y., Wen, Z., Zheng, W.-T., and Jiang, Q. (2017b). Lithium ion breathable electrodes with 3D hierarchical architecture for ultrastable and high-capacity lithium storage. Adv. Funct. Mater. 27:1700447. doi: 10.1002/adfm.201700447

Li, Z., Bommier, C., Chong, Z. S., Jian, Z., Surta, T. W., Wang, X., et al. (2017c). Mechanism of Na-ion storage in hard carbon anodes revealed by heteroatom doping. Adv. Energy Mater. 7:1602894. doi: 10.1002/aenm.201602894

Li, Z., Xu, Z., Tan, X., Wang, H., Holt, C. M. B., Stephenson, T., et al. (2013). Mesoporous nitrogen-rich carbons derived from protein for ultra-high capacity battery anodes and supercapacitors. Energy Environ. Sci. 6, 871-878. doi: 10.1039/c2ee23599d

Lin, D., Liu, Y., Liang, Z., Lee, H. W., Sun, J., Wang, H., et al. (2016). Layered reduced graphene oxide with nanoscale interlayer gaps as a stable host for lithium metal anodes. Nat. Nanotechnol. 11, 626-632. doi: 10.1038/nnano.2016.32

Luo, W., Shen, F., Bommier, C., Zhu, H., Ji, X., and Hu, L. (2016). Na-ion battery anodes: materials and electrochemistry. Acc. Chem. Res. 49, 231-240. doi: 10.1021 acs.accounts.5b00482

Lv, W., Wen, F., Xiang, J., Zhao, J., Li, L., Wang, L., et al. (2015). Peanut shell derived hard carbon as ultralong cycling anodes for lithium and sodium batteries. Electrochim. Acta 176, 533-541. doi: 10.1016/j.electacta.2015.07.059

Ou, X., Xiong, X., Zheng, F., Yang, C., Lin, Z., Hu, R., et al. (2016). In situ X-ray diffraction characterization of $\mathrm{NbS}_{2}$ nanosheets as the anode material for sodium ion batteries. J. Power Sources 325, 410-416. doi: 10.1016/j.jpowsour.2016.06.055

Ou, X., Yang, C., Xiong, X., Zheng, F., Pan, Q., Jin, C., et al. (2017). A new rGOovercoated $\mathrm{Sb}_{2} \mathrm{Se}_{3}$ nanorods anode for $\mathrm{Na}^{+}$battery: in situ X-ray diffraction study on a live sodiation/desodiation process. Adv. Funct. Mater. 27:1606242. doi: 10.1002/adfm.201606242

Qie, L., Chen, W. M., Wang, Z. H., Shao, Q. G., Li, X., Yuan, L. X., et al. (2012). Nitrogen-doped porous carbon nanofiber webs as anodes for lithium ion batteries with a superhigh capacity and rate capability. Adv. Mater. 24, 2047-2050. doi: 10.1002/adma.201104634

Qin, J., He, C., Zhao, N., Wang, Z., Shi, C., Liu, E., et al. (2014). Graphene networks anchored with Sn@graphene as lithium ion battery anode. Acs Nano 8, 1728-1738. doi: 10.1021/nn406105n

Romanos, J., Beckner, M., Rash, T., Firlej, L., Kuchta, B., Yu, P., et al. (2012). Nanospace engineering of $\mathrm{KOH}$ activated carbon. Nanotechnology 23:015401. doi: 10.1088/0957-4484/23/1/015401

Shen, C., Long, H., Wang, G., Lu, W., Shao, L., and Xie, K. (2018). $\mathrm{Na}_{3} \mathrm{~V}_{2}\left(\mathrm{PO}_{4}\right)_{2} \mathrm{~F}_{3} @ \mathrm{C}$ dispersed within carbon nanotube frameworks as a high tap density cathode for high-performance sodium-ion batteries. J. Mater. Chem. A 6, 6007-6014. doi: 10.1039/C8TA00990B

Su, H., Zhang, H., Liu, F., Chun, F., Zhang, B., Chu, X., et al. (2017). High power supercapacitors based on hierarchically porous sheet-like nanocarbons with ionic liquid electrolytes. Chem. Eng. J. 322, 73-81. doi: 10.1016/j.cej.2017. 04.012
Tang, J., Etacheri, V., and Pol, V. G. (2016). From allergens to battery anodes: nature-inspired, pollen derived carbon architectures for room- and elevatedtemperature Li-ion storage. Sci. Rep. 6:20290. doi: 10.1038/srep20290

Wang, J., and Kaskel, S. (2012). KOH activation of carbon-based materials for energy storage. J. Mater. Chem. 22, 23710-23725. doi: 10.1039/c2jm34066f

Wang, X., Li, G., Hassan, F. M., Li, J., Fan, X., Batmaz, R., et al. (2015). Sulfur covalently bonded graphene with large capacity and high rate for high-performance sodium-ion batteries anodes. Nano Energy 15, 746-754. doi: 10.1016/j.nanoen.2015.05.038

Wang, Y., Kong, D., Huang, S., Shi, Y., Ding, M., Von Lim, Y., et al. (2018). 3D carbon foam-supported $\mathrm{WS}_{2}$ nanosheets for cable-shaped flexible sodium ion batteries. J. Mater. Chem. A 6, 10813-10824. doi: 10.1039/C8TA02773K

Wen, Y., He, K., Zhu, Y., Han, F., Xu, Y., Matsuda, I., et al. (2014). Expanded graphite as superior anode for sodium-ion batteries. Nat. Commun. 5:4033. doi: $10.1038 /$ ncomms5033

Wu, L., Buchholz, D., Vaalma, C., Giffin, G. A., and Passerini, S. (2016a). Apple biowaste-derived hard carbon as powerful anode material for Na-ion batteries. Chemelectrochem 3, 292-298. doi: 10.1002/celc.201500437

Wu, X., Li, Y., Xiang, Y., Liu, Z., He, Z., Wu, X., et al. (2016b). The electrochemical performance of aqueous rechargeable battery of $\mathrm{Zn} / \mathrm{Na}_{0.44} \mathrm{MnO}_{2}$ based on hybrid electrolyte. J. Power Sources 336, 35-39. doi: 10.1016/j.jpowsour.2016.10.053

Wu, X., Xiang, Y., Peng, Q., Wu, X., Li, Y., Tang, F., et al. (2017). Greenlow-cost rechargeable aqueous zinc-ion batteries using hollow porous spinel $\mathrm{ZnMn}_{2} \mathrm{O}_{4}$ as the cathode material. J. Mater. Chem. A 5, 17990-17997. doi: $10.1039 / \mathrm{C} 7 \mathrm{TA00100B}$

Xiong, J., Pan, Q., Zheng, F., Xiong, X., Yang, C., Hu, D., et al. (2018). N/S co-doped carbon derived from cotton as high performance anode materials for lithium ion batteries. Front. Chem. 6:78. doi: 10.3389/fchem.2018.00078

Xiong, X., Wang, G., Lin, Y., Wang, Y., Ou, X., Zheng, F., et al. (2016). Enhancing sodium ion battery performance by strongly binding nanostructured $\mathrm{Sb}_{2} \mathrm{~S}_{3}$ on sulfur-doped graphene sheets. ACS Nano 10, 10953-10959. doi: 10.1021/acsnano.6b05653

Xiong, X., Yang, C., Wang, G., Lin, Y., Ou, X., Wang, J.-H., et al. (2017). SnS nanoparticles electrostatically anchored on three-dimensional N-doped graphene as an active and durable anode for sodium-ion batteries. Energy Environ. Sci. 10, 1757-1763. doi: 10.1039/C7EE01628J

Yang, C., Ou, X., Xiong, X., Zheng, F., Hu, R., Chen, Y., et al. (2017). $V_{5} S_{8}$-graphite hybrid nanosheets as a high rate-capacity and stable anode material for sodiumion batteries. Energy Environ. Sci. 10, 107-113. doi: 10.1039/C6EE03173K

Yang, C., Xiong, J., Ou, X., Wu, C.-F., Xiong, X., Wang, J.-H., et al. (2018). A renewable natural cotton derived and nitrogen/sulfur co-doped carbon as a high-performance sodium ion battery anode. Mater. Today Energy 8, 37-44. doi: 10.1016/j.mtener.2018.02.001

Yu, W., Wang, H., Liu, S., Mao, N., Liu, X., Shi, J., et al. (2016). N, O-codoped hierarchical porous carbons derived from algae for highcapacity supercapacitors and battery anodes. Mater. Chem. A 4, 5973-5983. doi: $10.1039 /$ C6TA01821A

Zhang, N., Wang, Y., Jia, M., Liu, Y., Xu, J., Jiao, L., et al. (2018a). Ultrasmall Sn nanoparticles embedded in spherical hollow carbon for enhanced lithium storage properties. Chem. Commun. 54, 1205-1208. doi: 10.1039/C7CC09095A

Zhang, Q., Chen, H., Luo, L., Zhao, B., Luo, H., Han, X., et al. (2018b). Harnessing the concurrent reaction dynamics in active $\mathrm{Si}$ and Ge to achieve high performance lithium-ion batteries. Energy Environ. Sci. 11, 669-681. doi: 10.1039/C8EE00239H

Zhang, Q., Han, K., Li, S., Li, M., Li, J., and Ren, K. (2018c). Synthesis of garlic skinderived 3D hierarchical porous carbon for high-performance supercapacitors. Nanoscale 10, 2427-2437. doi: 10.1039/C7NR07158B

Zhang, R., Li, N. W., Cheng, X. B., Yin, Y. X., Zhang, Q., and Guo, Y. G. (2017). Advanced micro/nanostructures for lithium metal anodes. Adv. Sci. 4:1600445. doi: 10.1002/advs.201600445

Zhang, Y., Foster, C. W., Banks, C. E., Shao, L., Hou, H., Zou, G., et al. (2016b). Graphene-Rich wrapped petal-like rutile $\mathrm{TiO}_{2}$ tuned by carbon dots for high-performance sodium storage. Adv. Mater. 28, 9391-9399. doi: 10.1002/adma.201601621

Zhang, Y.-C., You, Y., Xin, S., Yin, Y.-X., Zhang, J., Wang, P., et al. (2016a). Rice husk-derived hierarchical silicon/nitrogen-doped carbon/carbon nanotube 
spheres as low-cost and high-capacity anodes for lithium-ion batteries. Nano Energy 25, 120-127. doi: 10.1016/j.nanoen.2016.04.043

Zheng, F., Yang, C., Xiong, X., Xiong, J., Hu, R., Chen, Y., et al. (2015). Nanoscale surface modification of lithium-rich layered-oxide composite cathodes for suppressing voltage fade. Angew. Chem. Int. Ed. Engl. 54, 13058-13062. doi: 10.1002/anie.201506408

Zhu, Z., Liang, F., Zhou, Z., Zeng, X., Wang, D., Dong, P., et al. (2018), Expanded biomass-derived hard carbon with ultra-stable performance in sodium-ion batteries. J. Mater. Chem. A 6, 1513-1522. doi: 10.1039/C7 TA07951F

Zou, G., Wang, C., Hou, H., Wang, C., Qiu, X., and Ji, X. (2017). Controllable interlayer spacing of sulfur-doped graphitic carbon nanosheets for fast sodium-ion batteries. Small 13:1700762. doi: 10.1002/smll.2017 00762
Conflict of Interest Statement: KX, YL, WS, and GZ were employed by company Electric Power Research Institute of Guangdong Power Grid Co., Ltd.

The remaining authors declare that the research was conducted in the absence of any commercial or financial relationships that could be construed as a potential conflict of interest.

Copyright $\odot 2018 \mathrm{Xu}, \mathrm{Li}$, Xiong, Ou, Su, Zhong and Yang. This is an open-access article distributed under the terms of the Creative Commons Attribution License (CC $B Y)$. The use, distribution or reproduction in other forums is permitted, provided the original author(s) and the copyright owner(s) are credited and that the original publication in this journal is cited, in accordance with accepted academic practice. No use, distribution or reproduction is permitted which does not comply with these terms. 